\section{Lysimachia christinae 'Zixin': A New Groundcover Plant}

\author{
Wei Zheng, Xiao-dan Xu, Kai-Ge Zhao, and Longqing Chen ${ }^{\mathbf{1}}$ \\ College of Horticulture and Forestry Sciences, Huazhong Agricultural \\ University, Shizishan Street, Hongshan, Wuhan, Hubei Province 430070, \\ China
}

Additional index words. christina loosestrife, wild variation, plant introduction, cultivar

The genus Lysimachia L. contains $\approx 180$ species from subtropical and temperate regions in the northern hemisphere, and more than 150 species are native to China (Chen and $\mathrm{Hu}, 1989$ ). Some of them are used as commercial garden plants. Up to now, $\approx 30$ Lysimachia cultivars, especially color-leaf cultivars, were traded in North America, East Asia, and Europe. Lysimachia christinae Hance, a mat-forming herbaceous perennial endemic to China, commonly known as Christina loosestrife, is distributed extensively in south, southwest, and central China (Chen and $\mathrm{Hu}$, 1989) with a subtropical continental monsoon climate. In recent years, it has been grown as a groundcover plant in central China. Its characteristics of creeping stems, charming yellow flowers, and strong adaptability render it particularly valuable in landscaping design. Moreover, L. christinae has greater heat and drought tolerance than $L$. nummularia 'Aurea', which has been widely used as groundcover in China (Du et al., 2007; Xu, 2007). Although the wild-type $L$. christinae has green foliage, color-leaf variations in the wild are available by direct introduction. Reported here is a variation of L. christinae with colorful foliage.

\section{Origin}

A wild variation of $L$. christinae with maroon veins was discovered at Enshi County, neighbor to the Three Gorges, in 2004 by W. Zheng and L.Q. Chen. It was introduced to the nursery of Huazhong Agriculture University for testing its commercial value. In 2005, the plants were sent for evaluation to university cooperators in Hubei Province of China. After evaluation, the cultivar was named 'Zixin' (Voucher specimen, Zheng and Chen 0801, is in the Specimen Museum of Huazhong Agriculture University) in accordance with the International Code of Nomenclature for Cultivated Plants (Brickell et al., 2004).

\section{Description}

Plants used for describing were grown in full sun under common cultivation. Descriptions of

\footnotetext{
Received for publication 8 Dec. 2008. Accepted for publication 19 Jan. 2009.

${ }^{1}$ To whom reprint request should be addressed; e-mail chenlq0206@163.com.
}

color for plants are based on comparison with the Royal Horticulture Society Color Chart [Royal Horticulture Society (RHS), 1986].

'Zixin' plant has a uniform, creeping growth habit. Stems (20 to $60 \mathrm{~cm}$ long) are purple-red (RHS N57A) with procumbent branches and roots at basal nodes. The internodes are 2 to $6 \mathrm{~cm}$ in length. Leaves are ovate or cordiform, opposite, up to $3.0 \mathrm{~cm}$ long $\times 2.2 \mathrm{~cm}$ wide. Petioles are one-third to one-fourth as long as the leaf blade. The leaf margin is entire and the lamina on either side of the base tends to be slightly undulated. The upper surface of the leaf has a green (RHS 137C) interveinal area and brilliant dark purple-red (RHS 185B) venation (Fig. 1). Flowering occurs in late spring and lasts for $\approx 30 \mathrm{~d}$. With yellow (RHS 13B) corolla and red (RHS 41B) at the base (Fig. 1), solitary flowers (with pedicels $3 \mathrm{~cm}$ in length) in axils are very showy. All these traits make the spreading 'Zixin' plants like a colorful carpet (Fig. 2). After flowering, 'Zixin' has little seed as a result of a considerably low seed-setting rate $(0.21 \%)$.

\section{Performance}

Lysimachia christinae 'Zixin' were evaluated for performance in the nursery of
Huazhong Agriculture University, Wuhan. Growth tests were initiated using wellrooted, three-node terminal cuttings. Each 50 cuttings were grown in $75 \%, 47 \%$, and $22 \%$ shade and full sun by a completely randomized design. Light was limited by covering the outdoor plots with voile net or black woven shadecloth. The experiment was conducted under common management with average soil of moderate fertility and a temperature range from 10 to $32^{\circ} \mathrm{C}$. Seventyfive days (from May 5 to 20 Mar. 2008) later, data collected included number of branches, leaves, and flowers; average length of main stem and internode; mulch area; and shoot dry weight per plant.

'Zixin' plants that were $50 \mathrm{~m}^{2}$ were grown in the field with routine cultivation in 2005 to 2008 for additional evaluations: 1) disease and pest susceptibility; 2) flood tolerance in the rainy season; 3 ) reseeding or invasiveness; and 4) heat tolerance in July (average temperature of $29.6{ }^{\circ} \mathrm{C}$, maximum temperature of $39.0^{\circ} \mathrm{C}$ ) and freezing tolerance in January (average temperature of $2.6{ }^{\circ} \mathrm{C}$, minimum temperature of $-5.3{ }^{\circ} \mathrm{C}$ ): using L. nummunaria 'Aurea' as a control. Performance was evaluated by the

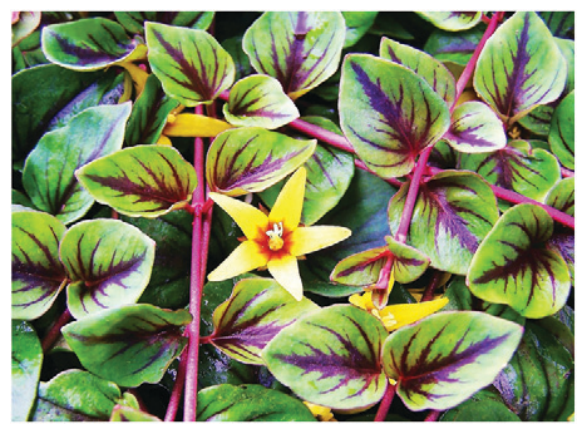

Fig. 1. Lysimachia christinae 'Zixin' leaves and flowers.

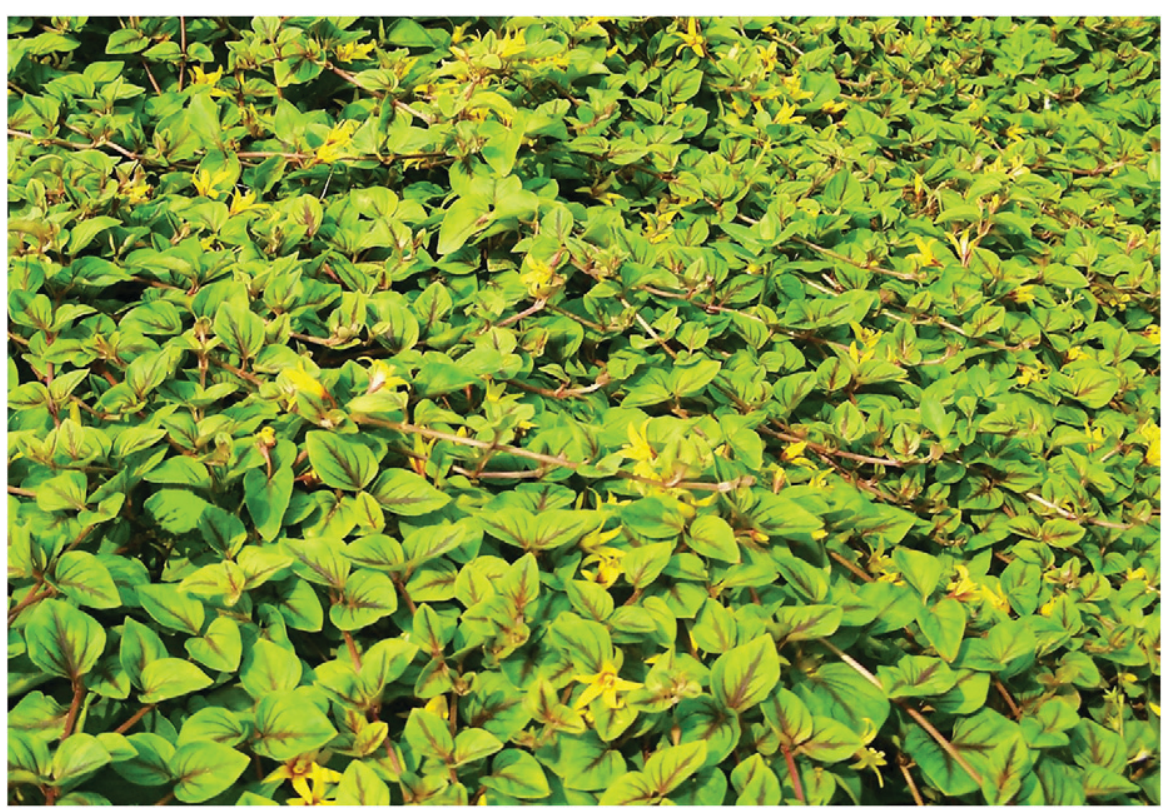

Fig. 2. Lysimachia christinae 'Zixin' used as groundcover. 
Table 1. Performance of Lysimachia christinae 'Zixin' in different shade.

\begin{tabular}{|c|c|c|c|c|c|c|c|c|}
\hline Shade $(\%)$ & $\begin{array}{c}\text { Avg. length } \\
\text { of internode }(\mathrm{cm})\end{array}$ & $\begin{array}{l}\text { Avg. area of } \\
\text { leaves }\left(\mathrm{cm}^{2}\right)\end{array}$ & $\begin{array}{l}\text { Avg. length of } \\
\text { main stem }(\mathrm{cm})\end{array}$ & $\begin{array}{c}\text { No. of } \\
\text { branches }\end{array}$ & $\begin{array}{l}\text { No. of } \\
\text { leaves }\end{array}$ & $\begin{array}{l}\text { No. of } \\
\text { flowers }\end{array}$ & Shoot dry wt (g) & Mulch area $\left(\mathrm{m}^{2}\right)$ \\
\hline 0 & $2.48 b^{z}$ & $5.28 \mathrm{~b}$ & $47.04 \mathrm{c}$ & $4.42 \mathrm{~d}$ & $91.23 \mathrm{~b}$ & 10.26 & $2.43 \mathrm{~b}$ & $0.68 \mathrm{~b}$ \\
\hline 22 & $2.66 \mathrm{~b}$ & $8.31 \mathrm{ab}$ & $73.62 \mathrm{~b}$ & $9.65 \mathrm{~b}$ & $138.95 \mathrm{a}$ & 10.92 & $4.15 \mathrm{a}$ & $0.88 \mathrm{a}$ \\
\hline 47 & $4.13 \mathrm{a}$ & $10.17 \mathrm{ab}$ & $83.30 \mathrm{a}$ & $11.46 \mathrm{a}$ & $136.08 \mathrm{a}$ & 11.14 & $4.13 \mathrm{a}$ & $0.93 \mathrm{a}$ \\
\hline 75 & $3.50 \mathrm{a}$ & $10.94 \mathrm{a}$ & $68.35 \mathrm{~b}$ & $7.42 \mathrm{c}$ & $94.14 \mathrm{~b}$ & 11.85 & $2.47 \mathrm{~b}$ & $0.73 \mathrm{~b}$ \\
\hline$R^{2}$ & 0.75 & 0.82 & 0.71 & 0.69 & 0.60 & 0.67 & 0.58 & 0.63 \\
\hline
\end{tabular}

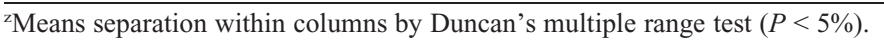

Table 2. Performance of Lysimachia christinae 'Zixin' in hot July and freezing January. ${ }^{\mathrm{z}}$

\begin{tabular}{|c|c|c|c|c|}
\hline \multirow[b]{2}{*}{ Cultivar } & \multicolumn{2}{|c|}{ Vigorous leaves $(\%)$} & \multicolumn{2}{|c|}{ Quality $^{\mathrm{y}}$} \\
\hline & July & January & July & January \\
\hline L. nummunaria Aurea & $26.32 b^{x}$ & $4.23 \mathrm{~b}$ & $1.35 \mathrm{~b}$ & $1.86 \mathrm{~b}$ \\
\hline L. christinae Zixin & $98.57 \mathrm{a}$ & $38.38 \mathrm{a}$ & $4.86 \mathrm{a}$ & $2.45 \mathrm{a}$ \\
\hline
\end{tabular}

${ }^{z}$ Value presented are means of five replications with $1 \mathrm{~m}^{2}$ of plants per year averaged over 4 years (2005 to 2008).

${ }^{\mathrm{y}}$ Visual rating in which 1 = poor, 3 = acceptable, $5=$ excellent quality.

${ }^{x}$ Means separation within columns by Duncan's multiple range test $(P<5 \%)$.

proportion of vigorous leaves and a visual quality rating in which $1=$ poor, 3 = acceptable, and $5=$ excellent quality. All data were analyzed using an analysis of variance and Duncan's multiple range tests.

Average leaf area and average internode length increased with increasing shade (Table 1), whereas number of leaves and branches, average length of the main stem, shoot dry weight, and mulch area fluctuated with increasing shade; peaked at $47 \%$ or $22 \%$ shade; and was significantly greater than $75 \%$ and of full sun. However, number of flowers showed no difference between these treatments. Shade also affected leaf color of 'Zixin'; the control group had green (RHS 137C) leaves with dark purple-red (RHS $185 \mathrm{~B})$ venation, whereas the plants in $75 \%$ shade showed dark green (RHS 137A) leaves with purple-brown (RHS 183A) venation. In conclusion, 'Zixin' is very adaptable to different light intensities. Therefore, it can be planted in full sun or under sparse trees.

Heat tolerance of 'Zixin' in July was significantly greater than that of $L$. nummu- naria 'Aurea' (Table 2) as well as freezing tolerance in January. Although the leaves on the stem base were injured by infrequent continued snowing for $\approx 20 \mathrm{~d}$ (average temperature of $\approx 0.5^{\circ} \mathrm{C}$ ) in Jan. 2008 (Fu et al., 2008), plants regrew quickly when the early spring approached.

During the observational years, we found that the seed-setting rate of 'Zixin' was $0.21 \%$. Moreover, no seedlings were observed in the field plantings. In the second-year plantings, vegetative propagates spread around but exhibited little invasiveness. The leaves of 'Zixin' remained green when the base part of the plants was flooded, whereas leaves turned yellow when the whole plants were flooded for $3 \mathrm{~d}$, but they resumed growing immediately. Furthermore, it was free of major diseases and grew well in average soil of moderate fertility. In addition, 'Zixin' is readily propagated by cuttings with rooting occurring within 1 week.

All the traits mentioned make it a satisfactory groundcover with desirable characteristics and little maintenance for urban landscaping in central China as well as North America and Europe with similar climates.

\section{Availability}

Lysimachia christinae 'Zixin' will be trademarked and is intended for groundcover. A patent application has been submitted to the Patent Office of Hubei Province, China. The plant patent rights will be assigned to Huazhong Agriculture University. Inquiries regarding 'Zixin' can be obtained by sending e-mail to chenlq0206@163.com. Plants for research purposes may be obtained directly from the author.

\section{Literature Cited}

Brickell, C.D., B.R. Baum, W.L.A. Hetterscheid, A.C. Leslie, J. McNeill, P. Trehane, F. Vrugtman, and J.H. Wiersema. 2004. International code of nomenclature for cultivated plants 7 th ed. Acta Hort. 647:1-84.

Chen, F.H. and C.M. Hu. 1989. Flora of China. $59: 1-160$.

Du, H.Y., G.L. Liu, X.J. Liu, and H. Zheng. 2007. The research of drought resistance about two ground cover plants. Hebei J. Forest. Orchard Res. 22:203-206.

Fu, J.J., S.L. Li, and Y.M. Wang. 2008. Influence of prior thermal state of global oceans on the formation of the disastrous snow storm in Jan. 2008. Clim. Environ. Res. 13:478-490.

Royal Horticulture Society. 1986. RHS colour chart. Royal Hort. Soc., London, UK.

Xu, G.F. 2007. Physiological process of drought resistance of two Lysimachia species. J. Northwest Forest. Univ. 22:12-14. 